\title{
The Culture of Institutional Governance AT A UNIVERSITY IN LAOS: AN ETHNOGRAPHIC EXPLORATION
}

\author{
Nanludet Moxoma \\ National University of Laos \\ Martin Hayden \\ Southern Cross University
}

\begin{abstract}
This paper reports on an ethnographic exploration of the culture of institutional governance at one of the five public universities in Laos. Drawing on documentary materials, on-site observations made over an extended period, and semi-structured interviews conducted with 31 academic managers from across all management levels at the site institution, the paper seeks to throw light on the institution's embedded practices of internal governance, as well as on the beliefs, values and aspirations associated with those practices. A constructivist and interpretive methodology was employed to generate data. The picture to emerge is one of a university hemmed in by State controls and ideology, in which there is an overwhelmingly bureaucratic and managerial culture, and in which a governance structure that could potentially support institutional and academic autonomy does not do so. Resource constraints also contribute to the institution's limited capacity to exercise autonomy.
\end{abstract}

Keywords: Laos, higher education, governance, autonomy, management, culture

\section{Introduction}

The Lao People's Democratic Republic (Lao PDR), better known as Laos, is a large, landlocked country, much of which is mountainous and sparsely populated. With a population of less than 7 million, Laos tends to attract less international attention than its more populous neighbours - China, Vietnam, Thailand, Myanmar and Cambodia. Most people in Laos live in lowland areas adjacent to the Mekong River, where Vientiane, the national capital, is also located. The national level of GDP per capita remains low, at only US\$2,353 in 2016 (The World Bank, 2018), and the economy relies heavily on agriculture. Over recent years, though, average economic growth rates of $7 \%$ per annum have been achieved, and a process of economic transition to enable more reliance on manufactured goods and the provision of services is well under way.

For 60 years, Laos formed part of the French colonial region of Indochina. Upon gaining independence in 1954, the country was plunged into a long and destructive civil war, the outcome of which was victory in 1975 by the communist forces. The Lao People's Revolutionary Party (hereafter referred to as the Party) assumed control and has remained in power ever since. It adopts a MarxistLeninist political outlook.

The Party determined in 1975 that a Soviet model of higher education would be implemented in Laos (Noonan, 2011). This model privileged mono-disciplinary, teaching-focused institutes and colleges. In 1996, however, in a sharp reversal of this policy, the National University of Laos (NUOL) was established as a comprehensive public university with a research as well as a teaching function. It is the leading university in Laos and in 2015-16 had an enrolment of more than 21,000 students (Ministry of Education and Sports [MOES], 2016). Since 1996, four other public universities, each

a Correspondence can be directed to: nanludet@yahoo.com 
modelled on NUOL, have been established. These universities are: Champasack University in Pakse, Souphanouvong University in Luang Prabang, the University of Health Sciences in Vientiane (it was formerly a faculty within NUOL), and Savannakhet University in Savannakhet. By 2015-16, these four newer universities had a collective enrolment of almost 15,000 students (MOES, 2016).

The higher education sector also includes 12 teacher education institutes and more than 80 private colleges. In 2015-16, the teacher education institutes had a total enrolment of 17,362 students, and the private colleges had a total enrolment of 36,310 students. Most private college enrolments in Laos are part-time, whereas nearly all public higher education institution enrolments are full-time.

The investigation reported in this paper addressed the culture of governance at one of the five public universities in Laos - its identity will be protected. In 2014 and 2015, one of the authors, who speaks Lao, undertook an ethnographic study of this university's governance culture, drawing on documentary materials, on-site observations made over an extended period, and semi-structured interviews conducted with 31 academic managers from across all management levels.

The investigation was instigated for several reasons. One concerned the need felt for university governance in Laos to become better aligned with international norms, especially concerning institutional autonomy. As Salmi $(2009$, p. 8) has observed, the autonomy of a university's governance is one of three important foundations for global success - the other two being the availability of ample resources and the availability of academic talent. Another reason for undertaking the investigation was curiosity about the extent to which a cultural perspective on the governance of a university in Laos could be insightful. In this regard, Tierney's (1988) account of the importance of culture as a force shaping what happens in higher education institutions provided a strong inspiration. He asserted:

Institutions certainly are influenced by powerful, external factors such as demographic, economic and political conditions, yet they are also shaped by strong forces that emanate from within. This internal dynamic has its roots in the history of the organization and derives its force from the values, processes, and goals held by those most intimately involved with the organization's workings. An organization's culture is reflected in what is done, how it is done, and who is involved in doing it. It concerns decisions, actions, and communication, both on an instrumental and a symbolic level. (p. 3).

The literature on higher education in Laos is sparse. The only recent works appear to be chapters by Phou (2006) and Ogawa (2008), and an article by Moxom and Hayden (2015). None of these publications explicitly addressed the culture of institutional governance in the higher education sector in Laos.

This paper reports on key themes to emerge from the investigation. To begin, the investigation's setting is sketched, and both its conceptual perspective and its methodological approach need to be introduced.

\section{The Setting}

The Party owns the political landscape in Laos. At its peak is the Party Central Committee, which establishes a policy framework for laws approved by the National Assembly and for decrees issued by the Prime Minister. Ministers then make decisions and approve plans for their portfolios. Regarding higher education, a Department of Higher Education within the Ministry of Education and Sports (MOES) is primarily responsible for developing plans and policies for the higher education sector. Presidents of public universities interpret these plans and policies. They are expected to implement them in a manner that aligns with Party priorities and values. Party cells within public universities monitor the extent of compliance in this regard. Because of Party scrutiny, academic managers are generally reluctant to take risks. One way of doing so is by referring difficult matters to a higher level of authority for decision. Not surprisingly, this pattern results in both centralization and congestion 
in decision-making. Stuart-Fox (2008) has described the political culture of decision-making in Laos as one in which "information flows up in the hierarchy, while decisions flow down" (p. 3). He has also observed that personal connections with a senior Party member can be a way of getting decisions made more quickly, but without appropriate transparency.

The Education Law authorises the Minister for Education and Sports to approve the higher education curriculum, establish academic standards, manage the appointment of staff, monitor and evaluate academic outcomes, and approve any international partnerships or forms of cooperation that may involve public higher education institutions. This authority means that, by international standards, universities in Laos have limited institutional autonomy. Tight (1992) identified six decision-making freedoms associated with institutional autonomy: freedom to exercise corporate self-governance; freedom to exercise corporate financial control; freedom to make staffing decisions; freedom to select students; freedom to determine the curriculum; and freedom to assess and certify student academic performance. Universities in Laos currently have access to only one of these freedoms, that is, the freedom to assess and certify student academic performance.

The Ministry has recently indicated a need to "strengthen ownership especially at university level" (MOES, 2015, p. 66). This statement has raised expectations that the governing boards of public universities, known as university councils, might soon be given more freedom to decide autonomously on a range of matters concerning institutional priorities, funding and administration. It is also possible, though, that the Ministry intends only to delegate more responsibility to university councils for supervising the application of the plethora of rules and regulations that currently apply to the functioning of universities in Laos. These rules and regulations derive from multiple Ministries within the Cabinet, and from the Party. They are not routinely updated and are of variable quality in terms of how well they have been drafted.

The governance structure for universities in Laos has the appearance of a corporate model of governance. Each university has a governing board, the university council, which is independently chaired, and which includes external members. According to Prime Ministerial Decree 071/PM, dated June 16, 2009, a university council is required to discharge the following responsibilities: approve policies, development plans and budget plans for the President to propose to the Government; approve rules, regulations and directives applying to institutional management; determine the appointment levels for academic and other members of staff; and implement regulations for quality assurance at the institution. Each university also has an academic committee, comprised entirely of members of academic staff. It is required to review the quality of teaching and learning at the university, having regard to standards specified in curriculum policy statements issued by the MOES.

In practice, however, a corporate form of institutional governance does not function well at universities in Laos. This point will be more fully developed later in this paper.

\section{Conceptual Perspective}

There is a vast international literature on higher education governance. Reviews of this literature by Hénard and Mitterle (2010), and by Austin and Jones (2015), are examples. Few of the studies undertaken have sought to explore specifically the culture of institutional governance, as found within individual higher education institutions. Kezar and Eckel (2004) could identify only three such studies up to the early 2000s. One of these was Birnbaum's (1988) exploration of the meanings given to the nature of 'good governance' by informants who were engaged with governance at different higher education institutions in the United States. Another was Lee's (1991) investigation of governance and leadership at eight higher education institutions, also in the United States. Lee found that past experiences of mistrust between academic staff members and senior academic managers impacted adversely on the quality of current institutional governance processes. The third was an investigation by Schuster, Smith, Corak and Yamada (1994) of planning and governance structures at different higher education institutions, again in the United States. They reported that institutional governance processes could be variously characterised according to the uniqueness of the institutional culture in 
which they were transacted. Kezar and Eckel (2004) strongly recommended that more investigations involving a cultural perspective on higher education governance were needed, but there is little evidence in the recent literature that this recommendation has been heeded.

This situation is surprising because, as Smerek (2010) has shown, there is an influential body of higher education literature in which a cultural perspective has been adopted. He observed also that a cultural perspective "offers powerful ways to understand deep-level, partly non-conscious sets of meanings, ideas, and symbols" (p. 381).

Alvesson (2002) succinctly characterises the nature of a cultural perspective on organisations at large as requiring a focus on:

... the meanings given by key actors to elements in their institutional environment, whether these elements are its social structures, its social behaviors or its characteristic forms of social relations. Culture, then, is central in governing the understanding of behavior, social events, institutions and processes. Culture is the setting in which these phenomena become comprehensible and meaningful. (p. 4)

Understanding the culture of governance at a public university in Laos requires an exploration of the institution's embedded practices of governance and of the beliefs, values and aspirations associated with those practices. It requires an understanding not only of how the institution is governed but also of how key actors perceive the governance of the institution.

\section{Methodology}

Lincoln and Guba's constructivist methodology of Naturalistic Inquiry (Lincoln \& Guba, 1985) provided a suitable framework for exploring the culture of governance at a public university in Laos. Naturalistic Inquiry requires that an investigation should be entirely discovery-oriented, as opposed to being framed by hypotheses and the manipulation of potentially salient variables. It also requires the researcher to be the primary data-gathering instrument. Guba and Lincoln (1981, pp. 129-138) identified characteristics of human beings that make them ideal as instruments for collecting and analysing data about social and cultural phenomena, including that, when collecting and analysing data, human beings are able to be responsive and adaptable, able to take account simultaneously of multiple layers of meaning, and able to process data at the same time as it is being collected. Lincoln and Guba (1985, p. 194) cautioned, however, that these benefits were lost if the data-gathering processes were not 'trustworthy', a quality which they identified as mirroring validity and reliability in positivist research. Operational strategies for establishing trustworthiness were said to include: prolonged engagement - spending a sufficient amount of time in the field to acquire a depth of familiarity with the phenomenon of interest; persistent observation - acquiring a depth of observational detail about the phenomenon; triangulation - using multi-methods of data collection concerning the phenomenon; peer debriefing - being able to report to knowledgeable peers about insights emerging from the data; and member checking - giving participants an opportunity to confirm both the accuracy of the data collected and the believability of interpretations given to that data by the researcher.

The site for the investigation was selected on the basis that its governance culture was likely to be broadly representative of the culture of governance across all five public universities in Laos. It was also an institution whose President expressed support for the proposed investigation. Academic managers (the president and Vice-presidents, Deans, Heads of institution-wide offices, Vice-deans, Heads of academic departments, and Deputy-heads of academic departments) from the site university were identified as the preferred participants in the investigation because of their greater likelihood of being able to provide rich information about the institution's governance culture. 
A sampling technique described by Patton (2002, p. 45) as "snowballing" was employed, whereby academic managers selected purposefully for interviews were then invited to recommend other academic managers who might valuably be interviewed. By the time data redundancy became evident, a total of 31 academic managers had contributed to the investigation. These participants were interviewed at length, in some cases several times, and their accounts were triangulated by means of direct on-site observations of governance practices, as well as by means of the analysis of relevant documentary materials.

Data collection took place initially over an intensive ten-week period of fieldwork in 2014. Each participant was subsequently provided with an opportunity to verify the interview data collected and to contribute further to the investigation. Extensive follow-up interviews and email discussions took place in 2015. The participants appeared to enjoy reporting on their experiences. There were, however, some challenges to be overcome. English has a rich and sophisticated vocabulary which includes terms such as 'accountability' and 'autonomy', but the meaning of these terms in the Lao language, which is more limited in its vocabulary, can only be conveyed by means of extended phrases and sometimes lengthy explanations.

Interviews were conducted at times and in locations preferred by the participants. All interviews were conducted in person and in the native Lao language of the participants. Interviews were scheduled to be of one hour in duration, but most participants wanted to talk for longer. The procedures employed for collecting data for the investigation had received prior approval from the ethics committee of an Australian university.

Fictitious names are employed when reporting direct quotes from the participants. Also, the site institution is referred to simply as 'the University'.

\section{Characteristics of the Institutional Governance Culture}

The culture of governance at the site University was widely reported by the participants to be centralised, bureaucratic, managerial, financially constrained and ideological. These characteristics are now documented.

\section{Centralised}

There was widespread agreement among the participants that it was the President who governed the University, and not the University Council. This situation appeared to contradict Prime Ministerial Decree 071/PM, dated June 16, 2009, which declared the University Council to be responsible for, amongst other things, approving policies, development plans and budget plans. When invited to comment on this apparent contradiction, various explanations were provided.

One of these explanations related to the fact that 15 of the 29 members of the University Council were also members of staff at the University, and most of these staff members were members of the President's Executive Board, an advisory body to the President with a membership that included the Vice-presidents, the Deans and various Heads of institution-wide offices. The President's Executive Board, which met on a monthly basis, and not twice each year as was the case with the University Council, served as the forum at which matters of importance to the University could be routinely decided by the President. At University Council meetings, therefore, a majority of members of the Council had already discussed the agenda items at meetings of the President's Executive Board, and so were already in agreement about how these matters should be decided.

Another explanation was that the 14 external members of the University Council (including the Chair) seldom challenged the President's recommendations. In part, this situation reflected a high level of respect accorded to the Office of President. It was also reportedly the case, though, that many of the external members (other than the Chair, who was a highly respected official appointed by the MOES) were irregular in their attendance at University Council meetings, had little apparent understanding of their role as members, and had no depth of appreciation of the issues affecting 
the University. The external members included one representative from each of the three mass organisations in Lao society (the Lao Trade Unions, the Lao Youth Organization and the Lao Women's Union) and 10 other community representatives appointed by the MOES. As Mr Viengsavanh, a Vice-president, explained:

Generally, the University Council does not function properly because members from outside the University don't have time to participate in meetings on a regular basis, and they don't understand very well the processes and circumstances of the University. A Council can't work properly if some of its members don't have the time to develop this understanding.

Mr Viengsavanh reported also that opportunities for in-depth discussion at University Council meetings were wasted because the community representatives had little or nothing to say. He commented: "I could clearly see that it was like having a meeting of people from different nations. The communication process simply did not function effectively." In his view, much of the blame for this situation was attributable to the lack of commitment of the community members.

It was the President, therefore, with advice from the President's Executive Board, who made the important governance decisions for the University. Even Mr Viengsavanh, who reported having worked strenuously to build the capacity of the University Council, acknowledged this fact:

The President's Executive Board has taken over the role of the University Council, and the President is the ultimate decision maker regarding University matters, which is not normally correct.

His reference to "not normally correct" reflected his belief that in a corporate model of governance, as practised in other, more developed Southeast Asian higher education systems, the University Council, as the institutional governing board, should be the ultimate decision-making authority at the University. He could not see a corporate governance model ever being properly implemented at the University for reasons related to the strength of the President's Executive Board and the passivity of the external members of the University Council.

Meetings of the President's Executive Board were widely reported by participants to be orderly, systematic and businesslike. Mr Souchalid, a Vice-president, explained the culture of these meetings as follows:

There is a meeting every month at which issues are dealt with comprehensively. The President's Executive Board checks monthly management plans, reviews monthly achievements, and sets objectives to be achieved in the future. It is a forum at which the President can answer questions, and it is a forum for making suggestions to the President.

Mr Ongard, the Head of an institution-wide office, confirmed Mr Souchalid's account. He referred specifically to the capacity of the President's Executive Board to make decisions without delay:

Its strengths are that it has the authority required to deal with issues of concern to NUOL. It includes all the important managers at the University. They can talk and make decisions immediately when that is required.

Concerns were also expressed, though, about the extent of the President's personal freedom to dispense benefits and impose sanctions. Highly prized benefits in this regard included permissions to travel abroad and to serve on significant committees. These permissions conferred access to additional remuneration, mainly in the form of travel allowances and sitting fees. Some participants 
hinted also at the existence of opportunities for cronyism. One Head of an institution-wide office commented, for example: "Everyone involved with staffing appointments must act transparently. We must be able to recommend good people for advancement, whether the President likes them or not."

The Academic Committee, which was reported to be responsible for assuring the quality of teaching and learning at the University (though no documentation to this effect was sighted), was referred to in much the same way as the University Council, that is, as a committee with a formal role but with negligible authority. The Academic Committee also met twice annually. The President chaired these meetings, though many participants observed that the President usually stayed for only a short period of time before handing over the chair role to a Vice-president. His standard practice in this regard was widely interpreted as symbolising the lack of authority of the Academic Committee.

More than one-third of the members of the Academic Committee were also members of the President's Executive Board, and so agenda items for Academic Committee meetings had often been decided in advance at meetings of the President's Executive Board. In any event, recommendations from the Academic Committee had to be approved by the President before being forwarded to the University Council. Mr Viengsavanh, a Vice-president, explained:

Once [the Academic Committee] makes decisions, these are then forwarded to the President for action. These proposals mainly concern new curricula and programs requiring approval. To have full academic autonomy, though, the Academic Committee would need to be able to make decisions itself about teaching and learning, and about the expectations of lecturers. However, that's not what happens, mainly because the Academic Committee's proposals always need to be approved by the President's Executive Board, and then they are taken to the University Council for ratification.

Many participants referred to delays in the implementation of decisions taken by the Academic Committee. The most severe criticisms for these delays were directed at the MOES. Ms Sidsay, a Vice-dean, commented, for example:

The Academic Committee, and then the University Council, must wait for a long time for decisions by the Ministry, including on matters concerning professorial and associate professorial appointments, regulations concerning research, decisions regarding curriculum developments, and a range of other matters related to the development of teaching and learning. How can the University possibly catch up with the rest of the world when these kinds of delays occur?

Mr Souchalid, a Vice-president, considered, however, that the Academic Committee had itself to blame for some of the delays. He claimed:

The Academic Committee's procedures need to be improved in several respects. First, members don't have enough time to study the contents of the agenda when they receive it only two or three days before an Academic Committee meeting. Second, Academic Committee members themselves tend to be very deferential when making comments in meetings for fear of inviting repercussions, whether from another faculty member or from the University leadership. The other problem is that, when the Academic Committee cannot reach a consensus about a matter being discussed, it simply refers the problem on to the President and the University Council.

From his point of view, the Academic Committee lacked the will to make difficult decisions intended to uphold high academic standards. In these circumstances, higher-level authorities continued to justify the importance of their role in scrutinizing closely any recommendations made by the Academic Committee. 


\section{Bureaucratic}

The culture of governance at the University could clearly be seen to be bureaucratic. It was a culture that resonated strongly with descriptions given by Baldridge (1971) and Birnbaum (1988) of bureaucratic cultures in the context of higher education. Baldridge (1971) characterised a bureaucratic higher education culture as one in which there is a well-defined hierarchy of authority with a clear chain-of-command, an insistence on the use of formal channels for the flow of internal communications, and the need for all decisions to be framed by a rigidly applied body of rules and regulations. This account matched perfectly the culture of governance at the University, where it was evident from on-site observations as well as from participants' reports that there was a formal hierarchy of decision-making authority, an expectation that communications should occur through formal channels, and a preoccupation with ensuring that decisions taken could be justified by means of reference to relevant rules and regulations.

This culture was so familiar to most participants that they could not easily describe it objectively. A small number of participants who had worked or studied abroad in more developed higher education systems were generally better able to point to the bureaucracy of the University's governance culture. One of these was Mr Souksavang, a Vice-president, who discussed at length the cultural distinctiveness of the University when compared with universities in Australia and France. He expressed frustration about the time-consuming and often useless nature of the processes having to be followed to obtain decisions at the University and within the Lao higher education sector.

Another participant who expressed frustration was Mr Thammavong, a Dean, who argued that important decisions were not being made quickly enough. He explained:

The pace of social change is very fast and our governance mechanisms are not keeping up. For example, we [the Deans] cannot negotiate independently in forming collaborations with foreign partners. The existing process for obtaining approval is far too bureaucratic! We need first to develop a proposal, which then goes to the President's Executive Board, and then to the Ministry of Education and Sports, and then to the Ministry of Foreign Affairs. Our proposed partners need a quick response, but we can't give one. Some of these approvals take too long to process. In the meantime, we miss out.

Mr Thammavong also reported on the difficulty he and other Deans had in having to follow rules and regulations that sometimes were not clearly expressed and could even be contradictory. He referred specifically to the rules and regulations applying to PhD candidature:

Our first PhD program was conducted by means of coursework, but the national curriculum refers to it needing to have a research base. However, the regulations issued by the Ministry about what a research base requires lack sufficient detail. How can we follow the rules when the rules have been written in a way that is not clear?

These kinds of contradictions, he explained, meant that the safest option for an academic manager was often to do nothing.

Mr Thammavong was not alone in feeling burdened by the responsibility of having to interpret regulatory details when making decisions. Most other academic managers expressed similar concerns. They reported that many authorities produced regulations affecting the operation of the University. These authorities were said to include including the Prime Minister and Cabinet, the MOES, the Ministry of Finance, the Bank of Lao PDR, the Ministry of Foreign Affairs, the Ministry of Home Affairs, and the Party. Deans and the Heads of institution-wide offices were then placed awkwardly in having to interpret these regulations, with a serious risk of criticism from the Party if they failed to interpret them correctly. Yet the sheer volume of these regulations, and the many discrepancies found within them, made this role extremely onerous. 


\section{Managerial}

Not surprisingly, in light of its bureaucratic character, the culture of governance at the University was also described as being highly managerial. Status at the University was said to be attained by being appointed to a managerial position. Many participants were critical of this aspect of the University's culture. Speaking strongly about the matter, Mr Saengmanee, a Vice-dean, claimed:

The current management system gives more benefit to managerial positions. This is the wrong signal to send because it means that many staff members aspire mainly to be managers. There are few who want to be researchers. Real academic leaders are those who achieve distinction for producing scientific research. It is through teaching and research [and not through management] that universities serve communities, the nation, and the world.

Mr Thammavong, a Dean, also commented on the topic. From his point of view, academic managers very easily became entangled in management processes that achieved little more than to keep the institution running. In his opinion, there was no scope for them to address the more difficult issues affecting the academic community, especially issues affecting the quality of teaching and learning. He reflected:

We need to learn from others, but we are not generally all that receptive to new ideas. We do need to try to make our University more distinctive. There are some good things happening, and we should make use of our quality assurance system to identify them, as well as to identify the weaknesses. To achieve improvements, we need to focus on specific aspects of the University's performance, such as making sure that academic staff appointments are based on proven performance. We are mostly concerned with matters of quantity, such as whether we have enough lecturers, but there should also be a focus on whether the lecturers we have are sufficiently competent.

Mr Phimma, the Deputy-head of an academic department, explained that academic managers at the University were kept busy with administrative matters concerning student numbers, student grades, staffing arrangements, and compliance with annual, monthly, weekly and even daily plans. He argued that they were, therefore, not easily able to address fundamental questions about the quality of the learning experience for students. He reported: "Some lecturers can't even use PowerPoint, and so they teach without any teaching aids, simply by reading material from a book."

Most participants shared a view that insufficient attention was being given to the development of leadership skills. Mr Vithaya, the Head of an academic department, reported how the process for appointing managers was often very reactive:

We will soon have two or three more colleagues [academic managers] who are about to retire. I don't think [the University] has given any attention to how they will be replaced in time for business to continue as normal. [The University] needs to have a mechanism that allows new recruits to be appointed a year or so before existing academic managers retire. Instead, it waits until there is a problem.

A managerial issue of significance to the University's reputation concerned academic corruption. More than one-half of the participants made reference to the incidence of academic corruption at the University, but most declared the problem to be one that they could not individually do much to resolve. Mr Ongard, the Head of an institution-wide office, saw the problem to be related to a general acceptance of corruption in Lao society:

I wish to see corruption disappear from our country [said with laughter, indicating that he thought this wish was fanciful]. Corruption is a problem everywhere. Because of corruption, people working in public institutions do not behave ethically. I don't blame lecturers for 
not being ethical. They see other people in society as models. But it should be different at a university.

Some participants commented that they wanted to take a stand on academic corruption, but that they had to be careful not to appear to be showing up the deficiencies of their more senior colleagues. Some also expressed a sense of resignation to the fact that any initiative they might sponsor would achieve nothing because of a culture of tolerance of academic corruption at the University.

\section{Financially Constrained}

Various senior managers frequently expressed frustration about the way in which the Ministry of Finance could independently determine the University's income. Furthermore, the Ministry was reported to require that any unspent funds from annual budgets could not be carried over to following years. Mr Souchalid, a Vice-president, explained:

The operating budget the Ministry of Finance gives us must be spent within the year we receive it. If it is not fully spent, then any unspent funds are deducted from the following year's budget. Long-term financial planning is impossible under these circumstances. The existing budgetary arrangement will not allow us to show a profit.

The Ministry of Finance was also reported to have determined that any external earnings generated independently by the University should be deducted from the following year's annual budget. This meant that the University could do little to help itself in terms of generating more income.

The University was also reported to be in a straightjacket with respect to student tuition fee levels, which many participants viewed as being far too low, given that private colleges were charging three times as much for study programs which were widely regarded as being inferior to those offered by the University. Mr Souchalid stated, for example: "We want to see an increase in the level of student tuition fees, which at present are very low, but we are not allowed to have that."

The lack of funds was widely reported to impact adversely on morale, quality and opportunities to implement reform. Ms Chansopha, a Vice-dean, commented, for example: "The curriculum requires us to teach both theory and its application, but we have no laboratory resources for the conduct of experiments, and so teaching about the practical applications of theory is almost impossible." Mr Sengsoulee, the Head of an academic department, reported: "We no longer have an adequate teaching wage. Many lecturers go outside to teach. It is difficult to stop them." Mr Naphavan, a Dean, lamented: "The state of the livelihood of lecturers in my faculty is almost too bad to admit."

The problem of insufficient funds was so pressing for nearly all participants that it pushed other concerns, including concerns about the University's governance, into the background. Surprisingly, though, concerns such as those reported by Mr Sengsoulee, about the "many classrooms that are simply unusable because the tables and chairs are broken", appeared never to have been raised at meetings of the Academic Committee, even though it was principally responsible for addressing issues relating to the quality of teaching and learning at the University.

\section{Ideological}

The Party was clearly well represented at all levels of decision making at the University. Indeed, as reported by many participants, academic staff members serving on the University Council, the President's Executive Board and the Academic Committee could not conceivably have been elected or appointed to these bodies if they were not already committed Party members. In this way, the Party was intimately engaged with the governance of the University. 
The influence of the Party on the University's culture was widely acknowledged by the participants, who reported that it played an especially important role concerning the appointment of academic managers. The legitimacy of its influence was not seriously questioned, though various participants expressed concern that, because of its ideological orientation, it contributed to a pattern whereby management appointments were based mainly on political considerations rather than demonstrated managerial capability. Ms Chansopha, a Vice-dean, who was an active participant in Party affairs, was nonetheless critical of the decision-making process:

Leadership appointments are made through open invitations to nominate for appointment, followed by a process of anonymous voting. But those who are appointed to these positions should be properly trained for the roles they occupy, and not simply be members of staff who have completed [Party] political courses and who know only how to comply with Party political morals and manners. Our University President and our Deans should be at least as competent as their ASEAN peers!

Many participants reported that, as Party members, they were routinely required to attend Party meetings related to their level of management at the University. These meetings were intended to ensure that all decisions taken at the University reflected the will of the Party. The meetings were also reported to provide an opportunity for ensuring that anybody appointed to a managerial position remained subject to Party discipline. Many participants reported how Party committees functioned. Mr Sengsoulee, the Head of an academic department, reported, for example:

We meet regularly to discuss solutions for any behaviour that is considered 'off-track' in terms of Party ideology. We also appoint Party members to lead the three mass organizations. Our members nearly always belong to one or other of these three organizations.

Deans who were participants in the investigation referred often to the need for them to adhere to the 'Principle of Democratic Centralism' in their decision-making. This traditional Party principle enshrines the dual need for leadership positions to be filled democratically and for persons elected to leadership positions to follow strictly the policies and directions of those appointed at a higher level of authority. Deans expressed a clear understanding of the role of this Principle in ensuring that political authority remained centralized. Mr Thammavong, a Dean, explained the operation of the Principle in the context of staffing appointments in his faculty:

Deans have the right to nominate an academic staff member for appointment to a position of responsibility. While we have this right, we must also base our decisions on the Principle of Democratic Centralism. Once we have selected a person for appointment, we must submit the selection for [democratic] approval by members of the Party.

He proceeded to explain how the Principle impacted on his capacity as Dean to make decisions:

All decisions of this nature must conform to the policies of a higher authority. Suppose we wanted to have a research relationship with a foreign university. Before we could agree to be involved in any research projects, we must submit our proposal to the President for approval.

Governance underpinned by the 'Principle of Democratic Centralism' meant inevitably that all matters of importance had to be decided centrally by the President, or in a manner that was consistent with the President's interpretation of Party ideology. His decisions were, of course, also subject to approval by a higher authority in the form of the Minister for Education and Sports, who could reverse them. 


\section{Discussion}

Clark's (1983, p. 143) 'triangle of coordination' points to three possible sources of authority in the coordination of a higher education sector: the State, the market, and the academy. If the State is in control, then it makes all the important decisions concerning a higher education sector, including decisions about its programs, their delivery and their availability to students. These decisions are generally based on political priorities. Where the market dominates, the important decisions are made according to the forces of supply and demand, and economic priorities will prevail. If the academy dominates, then global academic norms and standards will determine how decisions are made. Across the area within the triangle, a mix of influences from all three sources eventually determines how the important decisions are resolved.

Based on the evidence available, it is safe to say that the decision-making environment of the site University was one dominated by the State. The participants reported at length how the MOES controlled most aspects of the curriculum, how the Party controlled most aspects of the appointment process for academic managers, and how the Ministry of Finance controlled most aspects of the budget. The State was, therefore, a dominant source of influence on the culture of governance at the University. Its principal agent was the President, who, through the President's Executive Board, exercised ultimate responsibility for all significant decisions taken at the University. The University Council and the Academic Committee, which in a corporate governance model might have constrained the extent of the President's authority, could not do so effectively because of the authority able to be exercised by the president, and because of the relative weakness of both the University Council and the Academic Committee.

Market forces had a negligible impact of the culture of governance of the University. Because of the financial control exercised by the Ministry of Finance, the extent of decision-making freedom able to be exercised by the University regarding its finances was limited. Various participants reported that the University had in the past been able to deliver a special English-language program on a feefor-service basis. The program was subsequently suspended at the request of the MOES for reasons presumed to relate to concerns about its quality. Many participants wanted the University to have more freedom to be entrepreneurial.

The academy appeared also to have a negligible impact on the culture of governance at the University. The investigation did not focus specifically on the role played in the governance of the University by professors and associate professors, but none of the participants made any reference to them playing any role in the governance of the University. One reason for not referring to them may well be that there were relatively few professorial and associate professorial appointments at the University. Having a PhD qualification is an essential requirement in Laos for appointment as a professor or associate professor, yet less than $7 \%$ of all academic staff members at universities in Laos have a PhD qualification.

The University's corporate governance design seemed contradictory in light of the reality that the University was effectively a service unit of the State. Only a few participants were able to discuss this situation knowledgeably because most participants were not familiar with how a corporate governance model normally functions. One participant, Mr Viengsavanh, a Vice-president, who was deeply knowledgeable of corporate governance, and who wished to see a corporate governance model become operationalised at the University, expressed a sense of resignation that such a development was unlikely anytime soon. A major obstacle to the effective implementation of a corporate governance model was the extent of the control over decision-making able to be exercised by the President's Executive Board, which dominated both the University Council and the Academic Committee.

This situation was not, however, the only anomalous aspect of the University's culture of governance. Another was that it was the President's Executive Board, and not the University Council, which was regarded by most participants to be responsible for determining the University's priorities. This situation contradicted a provision in the official Minimum Education Standards of 
Higher Education Institutions (MOES, 2013) that required the governing board of a university in Laos to play "an important role in defining [the] vision, mission, and goals, identifying priority issues to be addressed, and developing (viable) strategic plans and [a] master plan for the institutional development in compliance with existing decrees and regulations" (p. 2).

In fully developed corporate systems of university governance, a governing board normally has authority to appoint the university's chief executive office, together with other members of the university's executive management team. Nothing like this arrangement was even being envisaged at the site University. To many participants, the thought of the Prime Minister, and more broadly the Party, surrendering a capacity to appoint the University's President seemed fanciful. In short, the University remained to a large extent a traditional, State-controlled higher education institution.

\section{Concluding Remarks}

This paper has reported an ethnographic exploration of the culture of governance at a public university in Laos. The quality of governance of public universities in Laos is fundamental to their development and future regional significance. The existing culture of governance at one of them was important to explore for the purposes of establishing the current state of institutional governance within the higher education sector in Laos. Culture is an important phenomenon to explore. As Schein (2010) has observed: ". . . the forces that are created in social and organizational situations deriving from culture are powerful. If we don't understand the operation of these forces, we become victim of them" (p. 7).

The experiences of a selected group of participants who in 2014 and 2015 contributed to the present investigation suggest that the culture of governance at the site University is heavily bureaucratic and managerial, with decisions made in a 'top-down' fashion, and with power held by the President and centralized within the President's Executive Board. In this kind of setting, political priorities seem likely to prevail. Some participants who were familiar with how a corporate model of university governance functions expressed a wish to see this model properly applied at the University. The investigation reported suggests, however, that change from the current culture of governance, characterized by a traditional State control, will not occur in a rush in Laos.

\section{References}

Alvesson, M. (2002). Understanding Organizational Culture. California: SAGE.

Austin, I. and Jones, G. A. (2015). Governance of Higher Education: Global Perspectives, Theories, and Practices. New York: Routledge.

Baldridge, J. V. (1971). Models of University Governance: Bureaucratic, Collegial, and Political. Research and Development Memorandum No. 77, School of Education, Stanford University, California. ERIC Document 060825.

Birnbaum, R. (1988). How Colleges Work: The Cybernetics of Academic Organization and Leadership. San Francisco, CA: Jossey-Bass.

Clark, B. R. (1983). The Higher Education System: Academic Organisation in Cross-national Perspective. Berkeley: University of California Press.

Guba, E. G. and Lincoln, Y. S. (1981). Effective evaluation: Improving the usefulness of evaluation results through responsive and naturalistic approaches. San Francisco: Jossey-Bass.

Hénard, F. and Mitterle, A. (2010). Governance and Quality Guidelines in Higher Education: A Review of Governance Arrangements and Quality Assurance. Berlin: OECD.

Kezar, A. and Eckel, P. (2004). Meeting today's governance challenges. Journal of Higher Education, 75(4), pp. 371-399.

Lee, B. (1991). Campus leaders and campus senates. New Directions for Higher Education 75 (Fall), pp. 41-61.

Lincoln, Y. S. and Guba, E. G. (1985). Naturalistic Inquiry. California: SAGE. 
Ministry of Education and Sports (MOES). (2013). Minimum Standards of Higher Education Institutions. Vientiane: MOES.

Ministry of Education and Sports (MOES). (2015). Education and Sports Sector Development Plan 2016-2020. Vientiane: MOES.

Ministry of Education and Sports (MOES). (2016). Annex Matrix School Year 2015-16. Vientiane: MOES.

Moxom, N. and Hayden, M. (2015). Higher education in the Lao People's Democratic Republic: A profile and some contemporary challenges. Asia Pacific World, 6(1), pp. 63-75.

Noonan, R. (2011). Education in Lao People's Democratic Republic: Confluence of history and vision. In: C. Brock \& L. P. Symaco (Eds.). Education in Southeast Asia. Oxford: Symposium Books, pp. 69-94.

Ogawa, K. (2008). Higher education in Lao PDR. In: Y. Hirosato and Y. Kitamura (Eds.). The Political Economy of Educational Reforms and Capacity Development in Southeast Asia: Cases of Cambodia, Laos and Vietnam. Dordrecht: Springer, pp. 283-301.

Patton, M. Q. (Ed.). (2002). Qualitative Research and Evaluation Methods. California: SAGE.

Phou, K. X. S. (2006). Lao PDR. In: Higher Education in South-East Asia. Bangkok: UNESCO Asia and Pacific Regional Bureau for Education, pp. 69-99.

Salmi, J. (2009). The Challenge of Establishing World-class Universities. Washington DC: The World Bank.

Schuster, J., Smith, D., Corak, K., and Yamada, M. (1994). Strategic Academic Governance: How to Make Big Decisions Better. Phoenix, AZ: Oryx

Smerek, R. E. (2010). Cultural perspectives of academia: Toward a model of cultural complexity. In: Higher Education: Handbook of Theory and Research. Dordrecht: Springer, pp. 381-423.

Schein, E. H. (2010). Organizational Culture and Leadership (4th ed.). San Francisco, Calif.: Jossey-Bass. Stuart-Fox, M. (2008). Historical Dictionary of Laos. Scarecrow Press.

Tierney, W. G. (1988). Organizational culture in higher education: Defining the essentials. The Journal of Higher Education, 59(1), pp. 2-21.

Tight, M. (1992). Institutional autonomy. In: B. R. Clark \& G. Neave (Eds), The Encyclopaedia of Higher Education. Oxford: Pergamon, pp. 1305-13.

The World Bank. (2018). Education Statistics: All Indicators. Available at: http://data.worldbank. org/ [Accessed 27 February 2018] 